\title{
Offspring of Depressed Parents: 30 Years Later
}

\author{
Myrna M. Weissman, Ph.D., Priya Wickramaratne, Ph.D., Marc J. Gameroff, Ph.D., Virginia Warner, Dr.P.H., \\ Daniel Pilowsky, M.D., M.P.H., Rajni Gathibandhe Kohad, M.D, M.P.H., Helena Verdeli, Ph.D., Jamie Skipper, M.A., \\ Ardesheer Talati, Ph.D.
}

Objective: While the increased risk of psychopathology in the biological offspring of depressed parents has been widely replicated, the long-term outcome through their full age of risk is less known. The authors present a 30-year follow-up of biological offspring (mean age $=47$ years) of depressed (highrisk) and nondepressed (low-risk) parents.

Method: One hundred forty-seven offspring of moderately to severely depressed or nondepressed parents selected from the same community were followed for up to 30 years. Diagnostic assessments were conducted blind to parents' clinical status. Final diagnoses were made by a blinded M.D. or Ph.D. evaluator.

Results: The risk for major depression was approximately three times as high in the high-risk offspring. The period of highest risk for first onset was between ages 15 and 25 in both groups. Prepubertal onsets were uncommon, but high-risk offspring had over 10 -fold increased risk. The early onset of major depression seen in the offspring of depressed parents was not offset by later first onsets in the low-risk group as they matured. The increased rates of major

The increased risk of psychopathology in the offspring of depressed parents is widely known. The long-term consequences through the full age of risk based on longitudinal data are not. We report results from a follow-up of up to 30 years of biological offspring of depressed and nondepressed parents. Previous reports of these families occurred at 10- and 20-years follow-up when they were primarily adolescents (1) or young adults (2). The purpose is to determine whether the risk of psychopathology, morbidity, and mortality in offspring of depressed parents continues as they mature.

The high rate of psychopathology and impaired functioning in the offspring of depressed parents compared with nondepressed parents is one of the best replicated findings in psychiatry (3-9), showing at least a two- to threefold increased risk of major depression depending on how the phenotype is defined and how the control group is selected. There have been follow-ups of the offspring to determine continuity in well-designed studies. The longest studies have been 16 and 20 years $(10,11)$. However, the offspring were depression in the high-risk group were largely accounted for by the early onsets, but later recurrences in the highrisk group were significantly increased. The high-risk offspring continue to have overall poorer functioning and receive more treatment for emotional problems. There was increased mortality in the high-risk group (5.5\% compared with $2.5 \%$ ) due to unnatural causes, with a nearly 8 -year difference in the mean age at death ( 38.8 years compared with 46.5 years).

Conclusions: The offspring of depressed parents remain at high risk for depression, morbidity, and mortality that persists into their middle years. While adolescence is the major period of onset for major depression in both risk groups, it is the offspring with family history who go on to have recurrences and a poor outcome as they mature. In the era of personalized medicine, until a more biologically based understanding of individual risk is found, a simple family history assessment of major depression as part of clinical care can be a predictor of individuals at long-term risk.

Am J Psychiatry 2016; 00:1-9; doi: 10.1176/appi.ajp.2016.15101327 studied from birth so that outcomes did not cover the full age of risk.

There have also been longitudinal studies of depressed or anxious patients, independent of parental diagnosis (12-15), the longest being 44 years (16). However, to our knowledge, no published studies of high risk have followed offspring into adulthood. The longer follow-up through the full age of risk for major depression allows estimates of age-specific and cumulative lifetime rates of psychiatric disorders, morbidity, and mortality in samples known to be at risk.

\section{METHOD}

In the original study, probands (generation $1=\mathrm{Gl}$ ) with moderate to severe unipolar major depressive disorder were selected from outpatient specialty settings for the psychopharmacologic treatment of mood disorders. Nondepressed probands were selected, at the same time, from an epidemiologic sample of adults from the same community. They 
were required to have no lifetime history of psychiatric illness, as indicated by several interviews. Full details, summarized here, can be found elsewhere $(1,2,17,18)$. We report data from wave 5 or 6 (about 30 years after the first two waves). The procedures were kept similar across the waves, with few exceptions, to avoid introducing methods bias. Across all waves, the proband, spouse, and offspring were interviewed by independent interviewers who were blind to the clinical status of the previous generations and the subject's previous history. Two spouses of probands (G1) in the low-risk group subsequently developed major depression between waves 1 and 2, as determined by best-estimate diagnosis. These families were reclassified as having depressed probands. The subjects were all European Caucasian to reduce heterogeneity for future genetic studies, as was the custom when the study began.

\section{Study Groups}

The study began in 1982, and the last interviews were completed in 2015 (approximately 33 years later). There were six waves of interviews, at baseline and 2, 10, 20, 25, and 30 years. The 25 -year interview had a small sample recruited for MRI studies. In order to obtain the largest sample followed, we included any biological offspring (generation $2=\mathrm{G} 2$ ) who entered the study at wave 1 or 2 and was assessed at wave 5 or 6 .

Two hundred sixty-three offspring from 91 families were interviewed at wave 1 or 2 and became the cohort for these analyses. During the course of the study, we learned that one offspring was adopted, one was ineligible due to Down's syndrome, and 12 offspring died. The two ineligible offspring were removed from the denominator. Data on outcome over about 30 years were available on 159 offspring (159/261 [61\%]). The responders $(\mathrm{N}=147)$ did not differ from nonresponders $(\mathrm{N}=104)$ who were seen at wave 1 or 2 , and were still alive at wave 6 , on age, gender, risk group, or lifetime major depression at last interview.

All interview waves were approved by the institutional review board at New York State Psychiatric Institute/Columbia University. Written informed consent was obtained from adults, and written consent was obtained from parents with assent from minors.

\section{Assessments}

The assessments were described previously $(1,2)$. The diagnostic interview across all waves was the Schedule for Affective Disorders and Schizophrenia-Lifetime Version (SADS-L) for adults and the child version (Schedule for Affective Disorders and Schizophrenia for School-Age Children [K-SADS-E]) modified for DSM-IV when subjects were between ages 6 and $17(19,20)$. The Global Assessment Scale (GAS) was completed by best-estimate at each wave (21). This assessment, made on a 0 - to 100-point scale, provides an overall estimate of the person's current functional adjustment based on all available information. A child's version, the C-GAS, was used when the offspring were between ages 6 and 17 (22). Lower scores on the GAS or C-GAS indicate more overall impairment. Data on medical illnesses were collected using a standard medical checklist that includes 57 conditions and asking whether a doctor told the subject that he or she had the condition and whether medication was taken for it. This information was collected at each wave from the subject and/or, in the case of minors, from the parent about the child. The data from all waves were pooled to create a lifetime history of medical conditions. Ambiguous reports of medical problems were coded during the best-estimate process by a physician.

Information on mortality was obtained by report from one or more relatives and confirmed by the Social Security Death Master File (https://www.ssdmf.com) and/or an online obituary search engine (tributes.com, genealogybank.com, and/or legacy.com). Cause of death was obtained primarily by family informant, and if unknown, by death certificates or newspaper articles. No information could be obtained on three of the 261 subjects. All three subjects were high-risk offspring.

\section{Interviewers and Best-Estimate Procedures}

The diagnostic assessments were administered by trained doctoral- or master's-level mental health professionals who were blind to the clinical status of the parents and to previous history information. Training procedures remained the same across waves $(1,2)$. Multiple sources of information were obtained, including direct and informant interviews and medical records when available. Final diagnosis of all generations was based on the best-estimate procedure (23). At wave 5 , two experienced clinicians (D.P. and H.V.) who were not involved in the interviewing, independently and blind to the diagnostic status of the previous generation, reviewed all the material and assigned DSM-IV diagnoses and a GAS or C-GAS score. The two diagnosticians corated 178 randomly selected cases from all generations. Kappa scores for interrater reliability were good to excellent: major depressive disorder, 0.82; dysthymia, 0.89; anxiety disorder, 0.65; alcohol abuse/dependence, 0.94; and drug abuse/dependence, 1.00. At wave 6, best-estimate diagnoses were all done by D.P.

\section{Statistical Analysis}

Preliminary analyses of group differences in mean values for continuous outcomes by parental depression were tested using the $t$ test; ordinal outcomes were tested with the Kruskal-Wallis chi-square test; and categorical outcomes were compared by the chi-square test. Continuous outcomes were analyzed using linear regression with the offspring outcome, such as the C-GAS score, as the dependent variable and parental depression as the predictor variable (24). Crosssectional categorical outcomes (e.g., treatment variables) were analyzed using logistic regression. Age and sex of offspring were considered a priori to be confounding variables and were retained in every model. These analyses were performed by applying a generalized estimating equations approach (25) by means of the GENMOD procedure in the 
TABLE 1. Demographic Characteristics and Wave-Specific Response Rates of 147 Offspring (G2) Who Were Interviewed at Wave 1 and/or 2 and Again at Wave 5 and/or 6, by Parental (G1) Depression Status

\begin{tabular}{|c|c|c|c|c|c|c|c|c|c|c|c|c|}
\hline \multirow[t]{2}{*}{ Characteristic } & \multicolumn{3}{|c|}{ All Offspring ( $\mathrm{N}=147)$} & \multicolumn{3}{|c|}{$\begin{array}{l}\text { Offspring Having One or } \\
\text { More Parents With Major } \\
\text { Depressive Disorder (N=103) }\end{array}$} & \multicolumn{3}{|c|}{$\begin{array}{c}\text { Offspring Having No } \\
\text { Parent With Major } \\
\text { Depressive Disorder }(\mathrm{N}=44)\end{array}$} & \multicolumn{3}{|c|}{ Group Comparison } \\
\hline & $\mathrm{N}$ & $\%$ & & $\mathrm{~N}$ & $\%$ & & $\mathrm{~N}$ & $\%$ & & $x^{2}$ & df & $p$ \\
\hline \multirow[t]{2}{*}{ Female } & 84 & 57.1 & & 61 & 59.2 & & 23 & 52.3 & & 0.61 & 1 & 0.44 \\
\hline & Mean & SD & Range & Mean & SD & Range & Mean & SD & Range & $\mathrm{F}$ & df & $\mathrm{p}$ \\
\hline \multicolumn{13}{|l|}{ Age (years) } \\
\hline At first interview & 19.4 & 6.9 & $6.4-35.4$ & 19.7 & 7.2 & $6.4-35.4$ & 18.5 & 6.2 & $6.4-32.3$ & 0.94 & 1,145 & 0.34 \\
\hline At last interview & 47.4 & 7.1 & $29.4-62.5$ & 47.9 & 7.3 & $29.4-62.5$ & 46.3 & 6.4 & $33.7-59.2$ & 1.56 & 1,145 & 0.21 \\
\hline \multirow{2}{*}{$\begin{array}{l}\text { Number of years between } \\
\text { first and last interview }\end{array}$} & 28.1 & 2.8 & $20.0-32.3$ & 28.2 & 2.5 & $20.0-32.3$ & 27.8 & 3.3 & $20.9-31.8$ & 0.59 & 1,145 & 0.44 \\
\hline & Mean & SD & Range & Mean & SD & Range & Mean & SD & Range & $x^{2}$ & df & $p$ \\
\hline \multirow[t]{2}{*}{ Total number of interviews } & 5.0 & 0.9 & $2-6$ & 5.0 & 0.8 & $3-6$ & 4.8 & 1.1 & $2-6$ & $0.78^{a}$ & 1 & 0.38 \\
\hline & $\mathrm{N}$ & $\%$ & & $\mathrm{~N}$ & $\%$ & & $\mathrm{~N}$ & $\%$ & & $x^{2}$ & df & $p$ \\
\hline \multicolumn{13}{|l|}{ Response rate } \\
\hline At wave 3 & 140 & 95.2 & & 100 & 97.1 & & 40 & 90.9 & & 2.59 & 1 & $0.20^{b}$ \\
\hline At wave 4 & 130 & 88.4 & & 94 & 91.3 & & 36 & 81.8 & & 2.69 & 1 & 0.10 \\
\hline
\end{tabular}

a Kruskal-Wallis test.

${ }^{b}$ Fisher's exact test.

SAS software package (26), to estimate parameters and to adjust for potential nonindependence of outcomes for offspring from the same family. Survival analysis techniques adjusting for correlated survival times were used to estimate 1) the age-specific incidence rates of psychiatric disorder in 10-year intervals by using life-table methods and 2) cumulative lifetime rates of major depressive disorder in highversus low-risk offspring by gender, by means of a modified Kaplan-Meier method (27). Cox proportional hazards regression models (28) modified to adjust for clustered data were used, following the approach described by Lin and Wei (29). This approach consists of using a robust sandwich covariance matrix estimate to account for the intracluster dependence and was used to estimate the relative risks of disorder by parental depression status while controlling for potential confounding variables, by means of the SUDAAN software package. The adjustment for clustered data was necessary to account for potential nonindependence of outcomes for offspring from the same family. The mean number of offspring per family was $2.1(\mathrm{SD}=1.0)$, the median 2 , and the range $1-5$. None of these descriptives differed by risk group.

\section{RESULTS}

\section{Characteristics of Offspring}

At the 30-year follow-up, the offspring of depressed and nondepressed probands (G1) did not differ by gender $(57 \%$ female), mean age at first $(19.4$ years $[\mathrm{SD}=6.9])$ or last (47.4 years $[\mathrm{SD}=7.1]$ ) interview, mean number of interviews (mean $=5.0[\mathrm{SD}=0.9]$ ), or response rate at waves 3 or 4 (Table 1 ). The study was carried out over 33 years (1982-2015), and the mean number of years in the study was 28.1 (range $=20.0-32.3$ ).

\section{Cumulative and Age-Specific Rates of Psychiatric Disorders}

During the 30-year follow-up, the offspring of depressed parents, compared with nondepressed parents, had about a twofold increased risk of mood and anxiety disorders, mainly major depression (threefold risk) and phobia (Table 2). The phobias were primarily specific phobias ( $74 \%$ in the high-risk group and $89 \%$ in the low-risk group). Many had more than one type of phobia. None of the other offspring disorders differed significantly by risk group. Rates of drug dependence $(\mathrm{p}=0.09)$ and any disorder $(\mathrm{p}=0.06)$ being higher in the highrisk group fell short of statistical significance. These lifetime disorder rates were cumulated across interviews and bestestimate procedures conducted over many years, during which the same impairment criteria were not always included in standard DSM criteria. Therefore, these rates might include disorders that are milder and less impairing. To account for this possibility, we used mean GAS scores across all waves to identify subjects with impairing disorders. Tables S1, S2, and S3 in the data supplement accompanying the online version of this article show the disorder rates by risk group after applying GAS score cutoffs of 70, 75, and 80. Applying impairment criteria reduces the rates of disorder, but the relative risks remain similar regardless of impairment $(<75$ or $<80)$, about threefold for major depression and anxiety. The number of low-risk offspring with GAS scores $<70$ (i.e., highly impairing disorder) was too small to allow meaningful analysis. Nonetheless, using GAS scores $<70$, the relative risk for mood disorders was over 10 -fold in the high-versus low-risk group $(\mathrm{p}=0.03)$. Absolute rates of disorder cannot be obtained from a case-control study. It is the relative rates between groups that are important. The relative risks of disorders between high- and 
TABLE 2. Cumulative Rates of Psychiatric Disorders in Offspring (G2) of Depressed and Nondepressed Parents (G1)

\begin{tabular}{|c|c|c|c|c|c|c|c|}
\hline \multirow{3}{*}{ Diagnosis in Offspring } & \multicolumn{4}{|c|}{ Cumulative Rate } & & & \\
\hline & \multicolumn{2}{|c|}{$\begin{array}{l}\text { Offspring Having One or } \\
\text { More Parents With Major } \\
\text { Depressive Disorder (N=103) }\end{array}$} & \multicolumn{2}{|c|}{$\begin{array}{c}\text { Offspring Having No } \\
\text { Parent with Major } \\
\text { Depressive Disorder }(\mathrm{N}=44)\end{array}$} & \multicolumn{3}{|c|}{ Analysis } \\
\hline & $\mathrm{N}$ & $\%$ & $\mathrm{~N}$ & $\%$ & Relative Risk $^{a}$ & $95 \% \mathrm{Cl}$ & $\mathrm{p}$ \\
\hline Any mood disorder & 88 & 85.4 & 27 & 61.4 & 2.02 & $1.26-3.22$ & 0.004 \\
\hline Major depressive disorder & 76 & 73.8 & 15 & 34.1 & 3.18 & $2.00-5.05$ & $<0.0001$ \\
\hline Bipolar I or II disorder & 17 & 16.5 & 3 & 6.8 & 2.60 & $0.72-9.35$ & 0.14 \\
\hline Dysthymic disorder & 41 & 39.8 & 14 & 31.8 & 1.36 & $0.71-2.60$ & 0.36 \\
\hline Any anxiety disorder & 74 & 71.8 & 21 & 47.7 & 2.02 & $1.26-3.25$ & 0.004 \\
\hline Phobia & 53 & 51.5 & 12 & 27.3 & 2.47 & $1.19-5.13$ & 0.02 \\
\hline Panic disorder & 15 & 14.6 & 3 & 6.8 & 2.37 & $0.68-8.24$ & 0.17 \\
\hline Obsessive-compulsive disorder & 5 & 4.9 & 0 & 0.0 & $-{ }^{\mathrm{b}}$ & - & - \\
\hline Generalized anxiety disorder ${ }^{c}$ & 16 & 15.5 & 4 & 9.1 & 0.38 & $0.06-2.43$ & 0.30 \\
\hline Any substance abuse & 13 & 12.6 & 9 & 20.5 & 0.57 & $0.24-1.34$ & 0.19 \\
\hline Any substance dependence & 26 & 25.2 & 7 & 15.9 & 1.73 & $0.71-4.24$ & 0.23 \\
\hline Alcohol dependence & 19 & 18.5 & 6 & 13.6 & 1.41 & $0.53-3.74$ & 0.49 \\
\hline Drug dependence & 13 & 12.6 & 1 & 2.3 & 5.91 & $0.76-46.07$ & 0.09 \\
\hline Schizophrenia & 2 & 1.9 & 0 & 0.0 & $-b$ & - & - \\
\hline Any of the disorders above & 96 & 93.2 & 34 & 77.3 & 1.54 & $0.97-2.43$ & 0.06 \\
\hline
\end{tabular}

a Adjusted for gender and age at the last interview of the offspring using Cox proportional hazards regression models; possible nonindependence of outcomes of family members was adjusted for by using the SUDAAN software package.

${ }^{b}$ Cannot be reliably calculated.

${ }^{c}$ Includes overanxious disorder of childhood.

FIGURE 1. Age-Specific Rates of Major Depressive Disorder (MDD) Over 30 Years in Offspring of Depressed and Nondepressed Parents

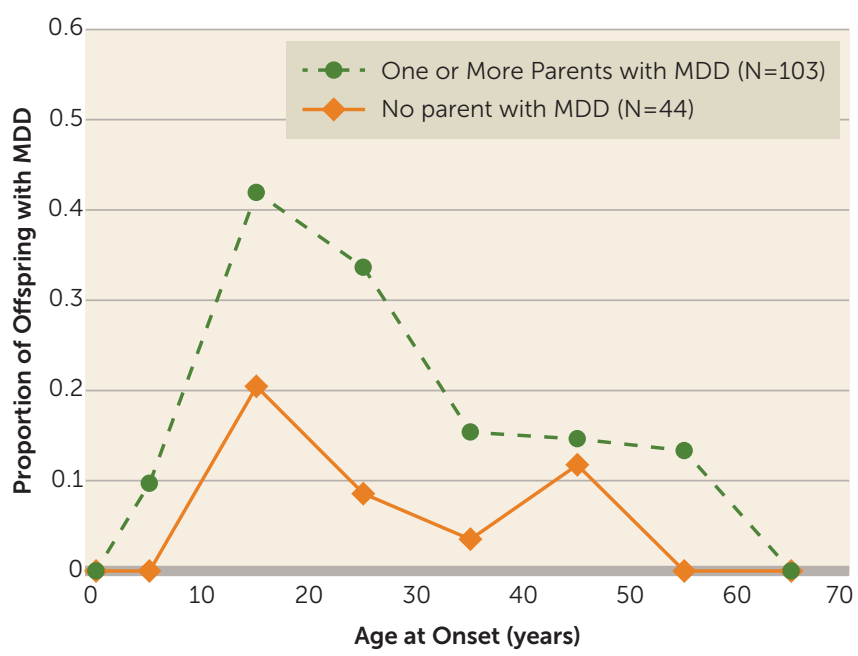

low-risk offspring were similar regardless of impairment criteria.

Figure 1 shows that even with a 30-year follow-up, the peak incidence for major depression remains late adolescence (mean age $=19.5$ years [SD=10.2]), with similar patterns of onset in the high- and low-risk groups and a threefold increased rate in the high-risk group, as found in the 20-year follow-up. Prepubertal onset major depression (before age 13) was uncommon. Whereas the cumulative risk of major depression for high-risk offspring was nearly triple that of the low-risk group, the relative risk of prepubertal onset major depression was 10-fold (relative risk $=10.7,95 \%$ confidence interval $[\mathrm{CI}]=1.5-76.4$ ). The longer follow-up shows a small increase in onsets of major depression at around 45 years in the offspring of low-risk parents, all in women. Due to the small numbers, we did not test for significance.

Since our lifetime rates of major depression by risk group are strongly affected by the early onset, we compared risk groups on depression onsets between ages 20 and 40 and between ages 40 and 60 . In each analysis, we excluded offspring who had already had an onset of depression before the age range being examined. Figure $\mathrm{S} 1$ in the online data supplement shows that the failure curves were significantly different (log-rank chi-square $=9.49, \mathrm{df}=1, \mathrm{p}=0.002$ ), with the high-risk group showing significantly greater risk for first depression at ages 20-40 compared with the low-risk group. However, starting at age 40 and ending at age 60, and including in the analysis offspring who did not have a depression episode prior to age 40, the failure curves for the two risk groups were not significantly different (see Figure S2 in the data supplement).

We also did a check on recurrence risk in offspring with early-onset $(<20$ years old) major depression by risk group. We found that high-risk offspring with early-onset major depression had an increased risk of recurrence after age 20 $(p=0.0013)$, whereas the low-risk offspring did not. These findings, while based on a small sample, suggest that most of the familial risk of major depression was based on the earlyonset cases and that recurrence risk among high-risk offspring was also significantly increased.

Figure 2 shows the cumulative rates of major depression by age at onset by gender. The rates of major depression are 
FIGURE 2. Cumulative Rates of Major Depressive Disorder (MDD) Over 30 Years in Female and Male Offspring of Depressed and Nondepressed Parents

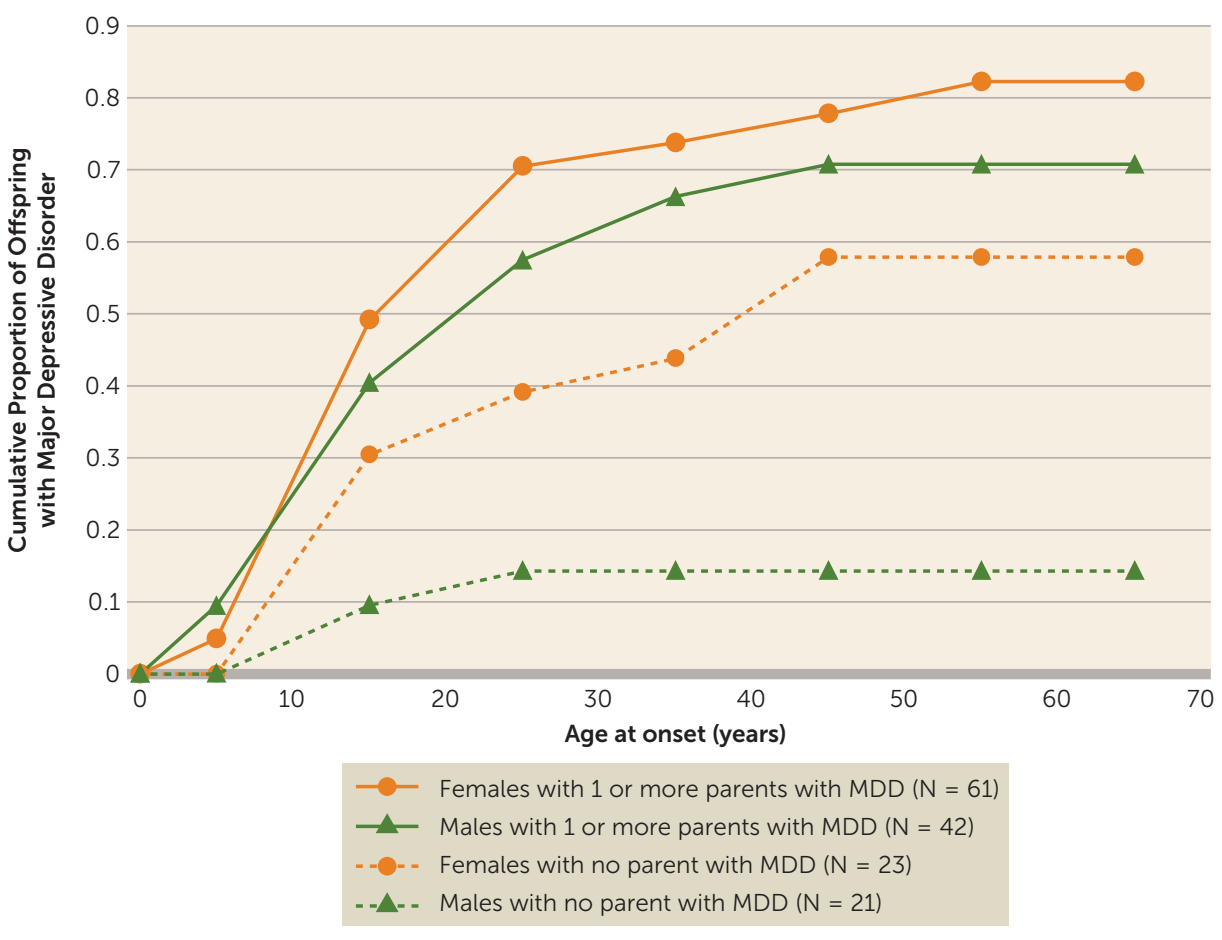

FIGURE 3. Age-Specific Rates of Any Anxiety Disorder Over 30 Years in Offspring of Depressed and Nondepressed Parents ${ }^{\mathrm{a}}$

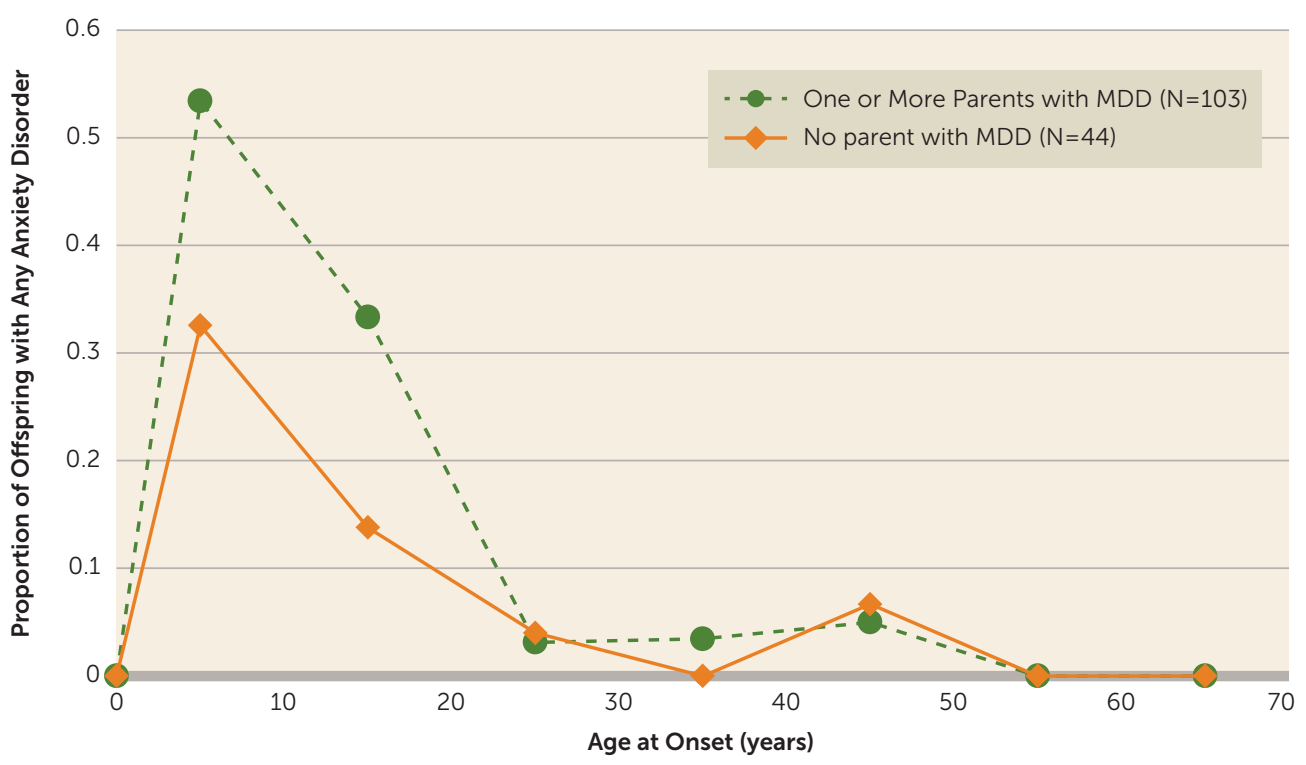

${ }^{a}$ Abbreviation: $M D D=$ major depressive disorder.

overall higher in women than men. However, among highrisk offspring, there are no statistically significant differences in cumulative rates of depression over time by gender $(\mathrm{F}=0.88, \mathrm{df}=1,54, \mathrm{p}=0.35)$. Conversely, among low-risk offspring, the cumulative rates of depression were significantly higher in females compared with males, with a greater than fourfold increase in cumulative rates among women by age 65 (relative risk $=4.89$, 95\% CI=1.33-17.94).

The earlier age at onset pattern for anxiety disorders compared with that for major depression is shown in Figure 3. As we found at the 20-year follow-up, the peak incidence of anxiety disorders (phobias, obsessive-compulsive disorder, generalized anxiety disorder, separation anxiety disorder, panic disorder) was before puberty or in early adolescence and much earlier than for major depression, especially in the offspring of depressed parents. There is no evidence of increased first onsets later. Phobias had the earliest onset, and panic disorder had onset in early adulthood.

As shown in Figure 4, the peak onset for substance dependence was also in adolescence or young adulthood, higher in the high-risk offspring at that period and largely in males.

\section{Impairment and Treatment}

By the 30-year follow-up, offspring of depressed parents were more likely to be separated or divorced and significantly more likely to have fewer children (Table 3). They also received significantly more and longer treatment for emotional problems, more continuous treatment, and more medication for emotional problems and overall were functioning more poorly $(\mathrm{p}=0.0003)$. The offspring by risk group did not differ by education, employment status, or income. We also compared the impairment scores (GAS) of the depressed offspring by risk group. The finding of depressed offspring of depressed parents having worse overall functioning (mean=76.1 $[\mathrm{SD}=9.2], \mathrm{N}=76$ ) than depressed offspring of nondepressed parents (mean=79.6 
FIGURE 4. Age-Specific Rates of Substance Dependence Over 30 Years in Offspring of Depressed and Nondepressed Parents ${ }^{a}$

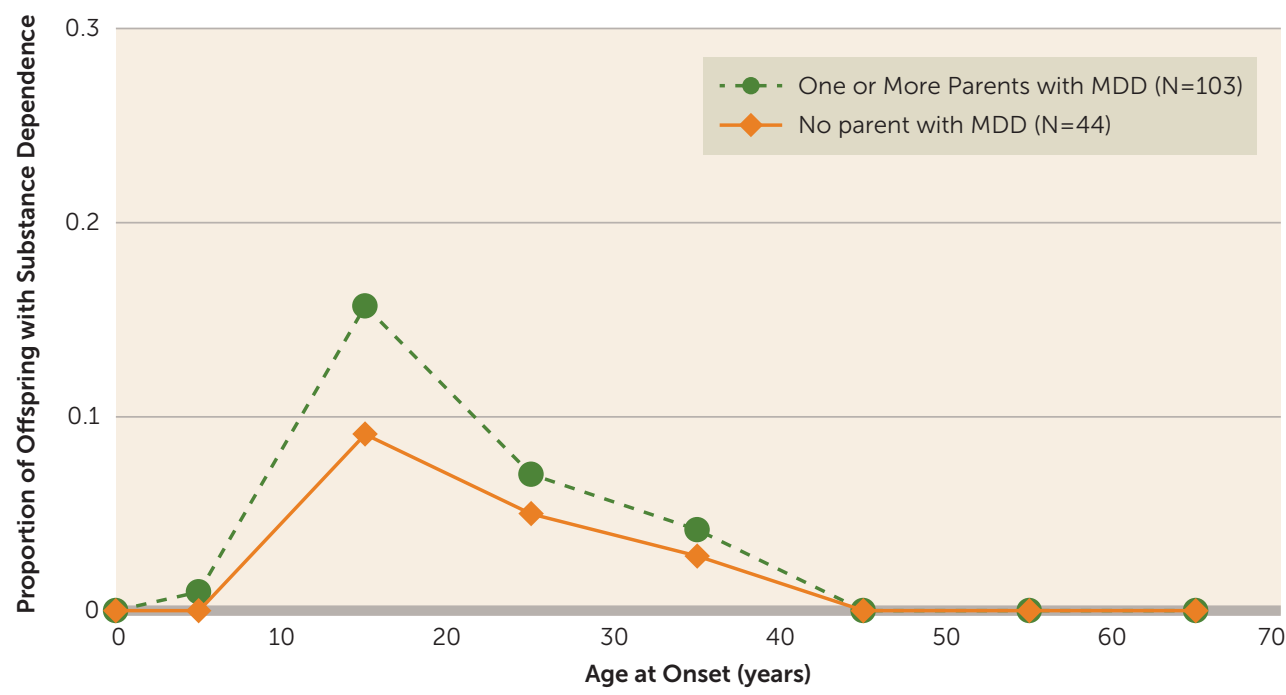

${ }^{a}$ Abbreviation: $M D D=$ major depressive disorder.

$[\mathrm{SD}=7.2], \mathrm{N}=15)(\mathrm{Z}=-1.75, \mathrm{p}=0.08)$ nearly reached statistical significance.

\section{Medical Conditions and Mortality}

At the 20-year follow-up, we saw significantly more medical conditions in the high-risk offspring, particularly cardiovascular and neuromuscular disorders. At the 30-year followup, there are no differences between risk groups (see Table $\mathrm{S} 4$ in the online data supplement). This is likely due to the lowrisk group developing more illnesses as they are now in middle age.

Mortality rates are based on the full cohort of offspring who participated in wave 1 or $2(\mathrm{~N}=261)$. The overall mortality rates were $5.5 \%$ (10 of 181) in the high-risk offspring and $2.5 \%$ ( 2 of 80 ) in the low-risk offspring. Deaths from natural causes were similar in both offspring groups ( $2.8 \%$ compared with $2.5 \%$ ). However, the difference in mortality between high- and low-risk offspring was in death from unnatural causes, in which $2.8 \%$ of the high-risk offspring and none of the low-risk offspring died from unnatural causes (suicide, $\mathrm{N}=2$; car accident, $\mathrm{N}=1$; overdose, $\mathrm{N}=2$ ). Four of these five deaths were in males; one death occurred at age 16, and the others at ages $30,39,42$, and 42 , respectively. The mean age at death from all causes was 38.8 years $(\mathrm{SD}=10.2)$ in the high-risk offspring and 46.5 years $(\mathrm{SD}=4.9)$ in the low-risk offspring, which approached statistical significance $(\mathrm{Z}=1.87, \mathrm{p}=0.06)$. Although the differences in offspring mortality rates are notable, the statistical tests were not significant, likely because death overall was relatively rare and left the tests underpowered. For instance, the test comparing the rates of $5.5 \%$ compared with $2.5 \%$ had an observed power of only 0.124 . This corresponds to a type II error rate of 0.876 (i.e., 1 - power), or an $87 \%$ probability of failing to reject an incorrect null hypothesis of no mortality difference between the high- and lowrisk offspring populations from which our samples derive.

\section{DISCUSSION}

The 30-year follow-up extends what was found at 20 years: the increased risk, over threefold, of major depression and anxiety disorder in the biological offspring of depressed compared with nondepressed parents; the onset of major depression in adolescence and early adulthood regardless of risk; a low prevalence but large increase (10-fold) in prepubertal onset major depression in the high-risk offspring; the onset of anxiety disorders before puberty or in early adolescence; and the increase in substance dependence in adolescence and young adulthood in the highrisk offspring.

The ages at onset of major depression, anxiety disorders, and substance dependence were consistent in both risk groups and with age at onset patterns in the general population (30). There are no new peak onset years in the highrisk group. The slight increase in first-onset major depression in low-risk women around age 45 may represent perimenopausal major depression, as described recently $(31,32)$.

The follow-up also shows increased morbidity and mental health treatment in the high-risk offspring, more divorces, fewer children, and overall poorer functioning. Decreased fertility in depressed patients, especially men, has been shown in recent studies from Sweden involving 2.3 million individuals between 1950 and 1970 (33). We did not find a gender difference in fecundity. Both men and women in the high- compared with low-risk group, whether or not they had major depression, had fewer children.

The increased risk of cardiovascular and neuromuscular diseases in the high-risk offspring seen at 20 years had disappeared, likely because the low-risk group of offspring has begun to "catch up." Medical problems have increased in both groups as they have aged.

Our high-risk offspring, who were mainly white and in midlife, had an early age of death from unnatural causes, mostly among males. Similarly, a rising mortality in midlife among white non-Hispanic men, largely accounted for by deaths from suicide and substance abuse, has been reported (34). A separate meta-analysis of mortality in subjects with mental disorders found that $17.5 \%$ of deaths were due to unnatural causes, with a median of 10 years of potential life lost (35).

Our study has several limitations. The sample size did not allow detailed comparisons by gender, specific disorders, or a host of environmental factors. The sample was underpowered 
TABLE 3. Demographic Characteristics, Mental Health Treatment, and Overall Functioning of 147 Offspring (G2) at Last Interview (Wave 5 or 6), by Parental (G1) Depression Status

\begin{tabular}{|c|c|c|c|c|c|c|c|}
\hline \multirow{3}{*}{ Variable } & \multicolumn{4}{|c|}{ Cumulative Rate Over 30 Years } & \multirow{2}{*}{\multicolumn{3}{|c|}{ Analysis }} \\
\hline & \multicolumn{2}{|c|}{$\begin{array}{l}\text { Offspring Having One or } \\
\text { More Parents With Major } \\
\text { Depressive Disorder (N=103) }\end{array}$} & \multicolumn{2}{|c|}{$\begin{array}{c}\text { Offspring Having No } \\
\text { Parent With Major } \\
\text { Depressive Disorder }(\mathrm{N}=44)\end{array}$} & & & \\
\hline & $\mathrm{N}$ & $\%$ & N & $\%$ & $x^{2}$ & df & $\mathrm{p}$ \\
\hline
\end{tabular}

Demographic characteristic ${ }^{a}$

Marital status

Ever separated or divorced

Currently married or widowed

Never married

wed

$\begin{array}{rrrr}30 & 29.7 & 8 & 18.6 \\ 51 & 50.5 & 31 & 72.1 \\ 20 & 19.8 & 4 & 9.3\end{array}$

\begin{tabular}{|c|c|c|c|c|c|c|c|}
\hline & Mean & SD & Mean & SD & $x^{2}$ & $d f$ & $\mathrm{p}$ \\
\hline Number of children & 1.5 & 1.1 & 2.1 & 1.3 & $6.24^{b}$ & 1 & 0.01 \\
\hline & $\mathrm{N}$ & $\%$ & $\mathrm{~N}$ & $\%$ & $x^{2}$ & df & $p$ \\
\hline $\begin{array}{l}\text { Education } \\
\text { High school diploma or less } \\
\text { Less than } 4 \text { years of college } \\
\text { Undergraduate degree } \\
\text { Graduate degree }\end{array}$ & $\begin{array}{l}35 \\
21 \\
26 \\
18\end{array}$ & $\begin{array}{l}35.0 \\
21.0 \\
26.0 \\
18.0\end{array}$ & $\begin{array}{r}13 \\
15 \\
10 \\
6\end{array}$ & $\begin{array}{l}29.6 \\
34.1 \\
22.7 \\
13.6\end{array}$ & 2.85 & 3 & 0.42 \\
\hline $\begin{array}{l}\text { Employment status } \\
\text { Full-time employment } \\
\text { Part-time or no employment }\end{array}$ & $\begin{array}{l}68 \\
33\end{array}$ & $\begin{array}{l}67.3 \\
32.7\end{array}$ & $\begin{array}{l}31 \\
13\end{array}$ & $\begin{array}{l}70.5 \\
29.6\end{array}$ & 0.14 & 1 & 0.71 \\
\hline & Mean & SD & Mean & SD & $x^{2}$ & df & $\mathrm{p}$ \\
\hline $\begin{array}{l}\text { Income } \\
\text { Individual } \\
\text { Household }\end{array}$ & $\begin{array}{l}\$ 51,000 \\
\$ 69,000\end{array}$ & $\begin{array}{l}29,000 \\
26,000\end{array}$ & $\begin{array}{l}\$ 58,000 \\
\$ 72,000\end{array}$ & $\begin{array}{l}26,000 \\
25,000\end{array}$ & $\begin{array}{l}1.89^{b} \\
0.68^{b}\end{array}$ & $\begin{array}{l}1 \\
1\end{array}$ & $\begin{array}{l}0.17 \\
0.41\end{array}$ \\
\hline & $\mathrm{N}$ & $\%$ & $\mathrm{~N}$ & $\%$ & $x^{2}$ & df & $\mathrm{p}$ \\
\hline
\end{tabular}

Mental health treatment

Outpatient

None

Brief period

Continuous for at least 6 months

Continuous for several years

Any outpatient treatment (percentage)

Any hospitalization (percentage)

Any psychotropic drug use (percentage)

Any of the above (percentage)

\begin{tabular}{ccc}
65 & 74 \\
\hline Mean
\end{tabular}

Overall functioning

Global Assessment Scale score (GAS) ${ }^{d}$

77.5

9.6

46.5

9.3

14.0

30.2

53.5

13.6

63.1

76.3

$\mathrm{SD}$

9.6

$6 \quad 83.3$

\footnotetext{
${ }^{a}$ All demographic characteristics are strictly current except for marital status, whose first category ("ever separated or divorced") includes historical information.

b Data were determined using the Kruskal-Wallis test.

c Data were determined using the Fisher's exact test.

'Mean of subjects' average GAS scores; each subject's average GAS score was calculated as the mean of all GAS scores given by the clinical best-estimator to the subject at each wave in which the subject was interviewed; higher scores denote better overall functioning.
}

to reach significance levels for mortality. There was only one comparison group, and the probands were selected from a treatment clinic, had moderate to severe depression, and were all white. While there were six waves of interviews over 30 years, more closely spaced assessments may have given better descriptions of risk, recurrence, or treatment.

Our study identifies a population at very high, long-term risk, the biological offspring of a depressed parent. Clinically, the findings show the possibility of preventing disability by targeting, in early adolescence, offspring of depressed parents who develop symptoms of depression. While both high- and low-risk offspring have their peak onsets of major depression in their youth, it is the high-risk offspring who have the recurrences and poor long-term course. The findings show the potential of a family history assessment. In the era of precision medicine, this simple clinical tool, family history, for targeting a high-risk population (the depressed offspring and parent) should not be overlooked. The variance explained 
by the human genome for common human diseases is often not susceptible to direct clinical or public health action (36). Simple clinical tools and interventions may be useful until a more biologically based understanding can be found. We, as well as others, have also shown the potential impact on the offspring of treating the depressed parent to remission, whether by medication (37-39) or psychotherapy (40). Even a highly efficacious prevention program for previously depressed adolescents was less effective if the parent was depressed (41). We do not know the long-term implications for the offspring into middle age, but in the short-term, successful treatment of a depressed parent may reduce morbidity in the offspring at a vulnerable age.

\section{AUTHOR AND ARTICLE INFORMATION}

From the Department of Psychiatry, College of Physicians and Surgeons, Columbia University, New York; the Mailman School of Public Health, Columbia University, New York; the Division of Epidemiology, New York State Psychiatric Institute, New York; and Teachers College, Columbia University, New York.

Address correspondence to Dr. Weissman (weissman anyspi.columbia.edu).

Drs. Weissman and Wickramaratne share first authorship.

Supported in part by NIMH grant R01 MH-036197 (principal investigator, Dr. Weissman), the Sackler Institute for Developmental Psychobiology, and the Silvio O. Conte Center (grant IP50MH090966; principal investigator, Jay Gingrich, M.D., Ph.D.)

Dr. Weissman has received funding from the National Institute on Drug Abuse, NARSAD, NIMH, the Sackler Foundation, and the Templeton Foundation; she also receives royalties from American Psychiatric Association Publishing, Multihealth Systems, Perseus Press, and Oxford University Press. Dr. Verdeli has received honoraria for psychotherapy training (Navy mental health staff and residents, Navy Medical Center Portsmouth; Fordham Institute for Humanitarian Studies [Ethiopia]; and StrongMinds [NGO, Uganda]) and for serving as keynote speaker at the Annual Meeting of the Society for Psychotherapy in Primary Care, University of Bologna, 2014; she has served as reviewer of psychotherapy supervision procedures for the World Bank Manual (Johns Hopkins University Press); she has received research funding from the International Medical Corps (NGO), as well as from Grand Challenges Canada; and she serves as Associate Editor of Global Mental Health. All other authors report no financial relationships with commercial interests.

Received Oct. 23, 2015; revision received Dec. 11, 2015; accepted Jan. 26 , 2016.

\section{REFERENCES}

1. Weissman MM, Warner V, Wickramaratne P, et al: Offspring of depressed parents: 10 years later. Arch Gen Psychiatry 1997; 54:932-940

2. Weissman MM, Wickramaratne $P$, Nomura $Y$, et al: Offspring of depressed parents: 20 years later. Am J Psychiatry 2006; 163:1001-1008

3. Lieb R, Isensee B, Höfler M, et al: Parental major depression and the risk of depression and other mental disorders in offspring: a prospective-longitudinal community study. Arch Gen Psychiatry 2002; 59:365-374

4. Klein DN, Lewinsohn PM, Seeley JR, et al: A family study of major depressive disorder in a community sample of adolescents. Arch Gen Psychiatry 2001; 58:13-20

5. Hammen C, Burge D, Burney E, et al: Longitudinal study of diagnoses in children of women with unipolar and bipolar affective disorder. Arch Gen Psychiatry 1990; 47:1112-1117

6. Goodman SH, Rouse MH, Connell AM, et al: Maternal depression and child psychopathology: a meta-analytic review. Clin Child Fam Psychol Rev 2011; 14:1-27
7. Garber J, Cole DA: Intergenerational transmission of depression: a launch and grow model of change across adolescence. Dev Psychopathol 2010; 22:819-830

8. Starr LR, Conway CC, Hammen CL, et al: Transdiagnostic and disorder-specific models of intergenerational transmission of internalizing pathology. Psychol Med 2014; 44:161-172

9. Rasic D, Hajek T, Alda M, et al: Risk of mental illness in offspring of parents with schizophrenia, bipolar disorder, and major depressive disorder: a meta-analysis of family high-risk studies. Schizophr Bull 2014; 40:28-38

10. Murray L, Arteche A, Fearon P, et al: Maternal postnatal depression and the development of depression in offspring up to 16 years of age. J Am Acad Child Adolesc Psychiatry 2011; 50:460-470

11. Hammen C, Hazel NA, Brennan PA, et al: Intergenerational transmission and continuity of stress and depression: depressed women and their offspring in 20 years of follow-up. Psychol Med 2012; 42:931-942

12. Ormel J, Raven D, van Oort F, et al: Mental health in Dutch adolescents: a TRAILS report on prevalence, severity, age of onset, continuity and co-morbidity of DSM disorders. Psychol Med 2015; 45:345-360.

13. Judd LL, Akiskal HS, Zeller PJ, et al: Psychosocial disability during the long-term course of unipolar major depressive disorder. Arch Gen Psychiatry 2000; 57:375-380

14. Beesdo-Baum K, Knappe S, Asselmann E, et al: The 'Early Developmental Stages of Psychopathology (EDSP) study': a 20-year review of methods and findings. Soc Psychiatry Psychiatr Epidemiol 2015; 50:851-866

15. Essau CA, Lewinsohn PM, Olaya B, et al: Anxiety disorders in adolescents and psychosocial outcomes at age 30. J Affect Disord 2014; 163:125-132

16. Angst J, Gamma A, Sellaro R, et al: Recurrence of bipolar disorders and major depression a life-long perspective. Eur Arch Psychiatry Clin Neurosci 2003; 253:236-240

17. Weissman MM, Gammon GD, John K, et al: Children of depressed parents: increased psychopathology and early onset of major depression. Arch Gen Psychiatry 1987; 44:847-853

18. Weissman MM, Wickramaratne $P$, Nomura $Y$, et al: Families at high and low risk for depression: a 3-generation study. Arch Gen Psychiatry $2005 ; 62: 29-36$

19. Kaufman J, Birmaher B, Brent D, et al: Schedule for Affective Disorders and Schizophrenia for School-Age Children-Present and Lifetime Version (K-SADS-PL): initial reliability and validity data. J Am Acad Child Adolesc Psychiatry 1997; 36:980-988

20. Orvaschel H, Puig-Antich J, Chambers W, et al: Retrospective assessment of prepubertal major depression with the Kiddie-SADS-e. J Am Acad Child Psychiatry 1982; 21:392-397

21. Endicott J, Spitzer RL, Fleiss JL, et al: The Global Assessment Scale: a procedure for measuring overall severity of psychiatric disturbance. Arch Gen Psychiatry 1976; 33:766-771

22. Shaffer D, Gould MS, Brasic J, et al: A Children's Global Assessment Scale (CGAS). Arch Gen Psychiatry 1983; 40:1228-1231

23. Leckman JF, Sholomskas D, Thompson WD, et al: Best estimate of lifetime psychiatric diagnosis: a methodological study. Arch Gen Psychiatry 1982; 39:879-883

24. Kleinbaum DG, Kupper LL, Muller KE: Applied Regression Analysis and Other Multivariate Methods. Boston, BWS-Kent, 1988

25. Liang KY, Zeer SL: Longitudinal data analysis using generalized linear models. Miometrika 1986; 73:13-22

26. SAS Software 9.3. Cary, NC, SAS Institute Inc, 2010

27. Williams RL: Product-limit survival functions with correlated survival times. Lifetime Data Anal 1995; 1:171-186

28. Cox DR: Regression models and life tables. Appl Stat 1972; 34: 187-220

29. Lin DY, Wei LJ: The robust interference for the proportional hazards model. J Am Stat Assoc 1989; 84:1074-1078

30. Kessler RC, Berglund P, Demler O, et al: Lifetime prevalence and age-of-onset distributions of DSM-IV disorders in the National 
Comorbidity Survey Replication. Arch Gen Psychiatry 2005; 62: 593-602 (Erratum in: Arch Gen Psychiatry, 2005 Jul; 62:768. Merikangas, Kathleen R [added])

31. Newhouse P, Albert K: Estrogen, stress, and depression: a neurocognitive model. JAMA Psychiatry 2015; 72:727-729

32. Schmidt PJ, Ben Dor R, Martinez PE, et al: Effects of estradiol withdrawal on mood in women with past perimenopausal depression: a randomized clinical trial. JAMA Psychiatry 2015; 72:714-726

33. Power RA, Kyaga S, Uher R, et al: Fecundity of patients with schizophrenia, autism, bipolar disorder, depression, anorexia nervosa, or substance abuse vs their unaffected siblings. JAMA Psychiatry 2013; 70:22-30

34. Case A, Deaton A: Rising morbidity and mortality in midlife among white non-Hispanic Americans in the 21st century. Proc Natl Acad Sci USA 2015; 112:15078-15083

35. Walker ER, McGee RE, Druss BG: Mortality in mental disorders and global disease burden implications: a systematic review and metaanalysis. JAMA Psychiatry 2015; 72:334-341
36. Joyner MJ, Paneth N: Seven questions for personalized medicine. JAMA 2015; 314:999-1000

37. Weissman MM, Pilowsky DJ, Wickramaratne PJ, et al: Remissions in maternal depression and child psychopathology: a STAR*D-child report. JAMA 2006; 295:1389-1398

38. Weissman MM, Wickramaratne P, Pilowsky DJ, et al: Treatment of maternal depression in a medication clinical trial and its effect on children. Am J Psychiatry 2015; 172:450-459

39. Garber J, Ciesla JA, McCauley E, et al: Remission of depression in parents: links to healthy functioning in their children. Child Dev 2011; 82:226-243

40. Swartz HA, Frank E, Zuckoff A, et al: Brief interpersonal psychotherapy for depressed mothers whose children are receiving psychiatric treatment. Am J Psychiatry 2008; 165:1155-1162

41. Brent DA, Brunwasser SM, Hollon SD, et al: Effect of a cognitivebehavioral prevention program on depression 6 years after implementation among at-risk adolescents: a randomized clinical trial. JAMA Psychiatry 2015; 72:1110-1118 